\title{
Study of Asssociation of Concha Bullosa with Rhinosinusitis
}

\author{
Shrikrishna B H, ${ }^{1}$ Jyothi A $C^{1}$
}

\section{Introduction}

ABSTRACT

There are several studies with contradictory findings about the role of concha bullosa with predisposition to rhinosinusitis. This study was conducted to assess the relationship of osteomeatal unit blockage with concha bullosa. Materials and methods

A cross-sectional observational study by radiological assessment of prevalence of chronic rhinosinusitis and blockage of ipsilateral osteomeatal unit was done on 100 cases of concha bullosa detected on computed tomography to determine the prevalence of chronic rhinosinusitis in subjects with concha bullosa and to examine the latter's relationship to osteomeatal unit blockage, which is a precursor for rhinosinusitis.

$\underline{\text { Results }}$

One hundred cases of concha bullosa were studied in a total of 87 CT scan films depicting concha bullosa. Some CT scans showed unilateral concha bullosa while few scans showed bilateral concha bullosa. Ipsilateral rhinosinusitis was found in only $31 \%$ of the sides in scans of subjects with concha bullosa. Of the total 100 concha bullosae studied, extensive type was the commonest followed by bulbous and lamellar variety.

\section{Discussion}

Although rhinosinusitis was more predominant in the extensive type of concha bullosa compared to other types, it was statistically not significant and there was no statistically significant association between any type of concha bullosa with ipsilateral rhinosinusitis either in right side or left side.

Conclusion

This study has found no statistically significant association between any type of concha bullosa with rhinosinusitis. A bigger study with larger sample size is required to better assess the strength of association between concha bullosa and rhinosinusitis. $\underline{\text { Kevwords }}$

Sinusitis; Turbinates; Tomography, X-Ray Computed Turbinates; Concha Bullosa; Osteomeatal Unit

$\mathrm{C}$ oncha bullosa is the presence of pneumatisation in the middle turbinate of the nose. ${ }^{1}$ According to Bolger et al., the pneumatisation of the middle conchais of three types: lamellartype is the pneumatisation of the vertical lamella of the concha; bulbous type is the pneumatisation of the bulbous segment; pneumatisation of both the lamellar and bulbous parts is called extensive concha bullosa. ${ }^{2}$ The middle turbinate pneumatisation is a part of the normal pneumatisation of the ethmoid air cells. ${ }^{1-3}$ Stammberger and Kennedy have defined osteomeatal unit as a functional unit of the anterior ethmoid complex representing the final common pathway for drainage and ventilation of the frontal, maxillary and anterior ethmoid cells. ${ }^{4}$ There are several studies with contradictory findings about the role of concha bullosa with predisposition to rhinosinusitis. ${ }^{2,5,6}$ The purpose of our study was to determine the possible relationship of concha bullosa to osteomeatal unit blockage, which is a precursor for rhinosinusitis by doing a radiological assessment.

\section{Materials and methods}

This cross-sectional observational study was carried out at the Department of ENT and Head Neck Surgery over a period of one year from 1st January 2015 to 31st December 2015 to determine the prevalence of

1 - Department of Otolaryngology and Head Neck Surgery, Navodaya Medical College, Raichur

\section{Corresponding author:}

Dr Shrikrishna B H

email: drshrikrishna@gmail.com 
chronic rhinosinusitis in subjects with CT scan showing presence of concha bullosa and to examine the possible relationship of concha bullosa with osteomeatal unit blockage, a precursor for rhinosinusitis. Our only inclusion criterion was presence of pneumatisation of middle turbinate, irrespective of the type and grade of pneumatisation. Since, our study aims at finding association between concha bullosa and rhinosinusitis, no other radiological parameters in the nose and paranasal sinus region was taken into consideration. This is an observational study and not an interventional study. This radiological assessment study included the scans which had been taken for evaluation of various features like headache or allergy. CT scans of patients with history of previous sinus surgery and facial trauma were excluded from our study. The CT machine used in our study was Pro-Speed Plus 4 Slice Multidetector CT machine. The sections were taken with slice thickness of $5 \mathrm{~mm}$.

One hundred cases of concha bullosa were selected in a total of $87 \mathrm{CT}$ scan films. Some CT scans showed unilateral concha bullosa while few scans showed bilateral concha bullosa. In all the 100 cases of concha bullosa, a search was done for presence of chronic rhinosinusitis on the side of concha bullosa. It has been shown that mucosal thickening less than $4 \mathrm{~mm}$ in chronic rhinosinusitis is not normally of clinical importance, even though these patients may still have symptoms. ${ }^{7}$ Hence, in our study, we have taken CT scan with $4 \mathrm{~mm}$ or more mucosal thickening in the sinus cavity as positive for chronic rhinosinusitis. Ipsilateral osteomeatal block is taken positive in case grayish opacity is noted in the osteomeatal unit area. The collected data was subjected to statistical analysis. Software used for analysis is Epi info version 6 and the test applied is Chi-Square test. Where ever the sample size was less for Chi-Square test, Fischer exact test was utilised.

Ethical considerations: The study got clearance by the Institutional Ethical Committee before its commencement. Also, a written informed consent was taken from all the patients whose CT scan films were included in the study.

\section{Results}

The age group of the subjects ranged between 21 to 48 years (average age was 28.4 years). There were 49 males $(56.3 \%)$ and 38 females (43.7\%). One hundred cases of concha bullosa were selected in a total of $87 \mathrm{CT}$ scan films. 46 scans showed unilateral concha bullosa on right side, 28 scans showed unilateral concha bullosa on left side and 13 scans showed bilateral concha bullosa. Of the total 100 concha bullosae studied, 46 (46\%) were of extensive type, $31(31 \%)$ were of bulbous type and $23(23 \%)$ were of lamellar type. Of the extensive type, 29 cases $(63 \%)$ were present on right side and 17 cases (37\%) were present on the left side. Of the bulbous type, 23 cases $(74.2 \%)$ were on right side and 8 cases $(25.8 \%)$ were on left side. Of the lamellar type, 14 cases $(60.9 \%)$ were on right side and 9 cases (39.1\%) were on left side.

In a total 100 cases of concha bullosa, ipsilateral rhinosinusitis was present in $31(31 \%)$ cases of concha bullosa (Figures 1 to 5). Of the 29 cases of extensive concha bullosa on the right side, 10 cases $(34.5 \%)$ had associated ipsilateral osteomeatal unit blockage and 19 cases $(65.5 \%)$ were free of ipsilateral osteomeatal unit blockage. Of the 17 cases of extensive concha bullosa on the left side, 7 cases $(41.2 \%)$ had associated ipsilateral osteomeatal unit blockage and 10 cases $(58.8 \%)$ were

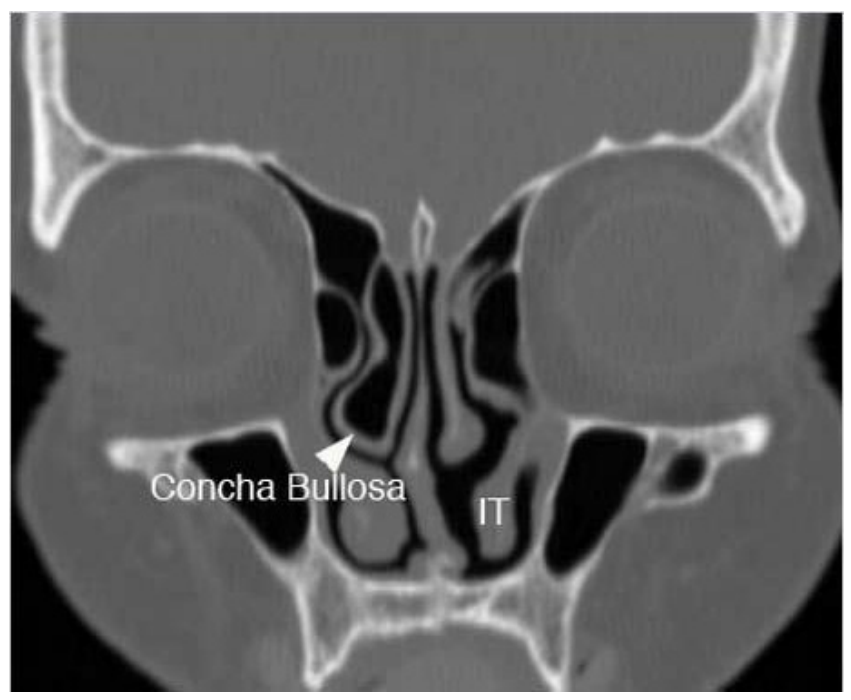

Fig.1. Right sided extensive concha bullosa with normal sinuses on ipsilateral side (IT- inferior turbinate) 
Table I : Association of rhinosinusitis with different types of concha bullosa

\begin{tabular}{|c|c|c|c|c|c|c|}
\hline SL. NO & $\begin{array}{c}\text { CONCHA } \\
\text { BULLOSA } \\
\text { TYPE AND } \\
\text { SIDE }\end{array}$ & $\begin{array}{c}\text { ASSOCIATED } \\
\text { WITH } \\
\text { RHINOSINUSITIS }\end{array}$ & $\begin{array}{c}\text { NOT ASSOCIATED } \\
\text { WITH } \\
\text { RHINOSINUSITIS }\end{array}$ & TOTAL & $\begin{array}{l}\text { CHI- } \\
\text { SQUARE } \\
\text { VALUE }\end{array}$ & P VALUE \\
\hline 1 & $\begin{array}{c}\text { Right } \\
\text { extensive }\end{array}$ & 10 & 19 & 29 & 0.23 & 0.63 \\
\hline 2 & $\begin{array}{c}\text { Left } \\
\text { extensive }\end{array}$ & 7 & 10 & 17 & 0.99 & 0.31 \\
\hline 3 & $\begin{array}{l}\text { Right } \\
\text { bulbous }\end{array}$ & 5 & 18 & 23 & 1.19 & 0.27 \\
\hline 4 & Left bulbous & 4 & 4 & 8 & $\begin{array}{c}\text { Fischers } \\
\text { Exact }\end{array}$ & 0.4 \\
\hline 5 & $\begin{array}{l}\text { Right } \\
\text { lamellar }\end{array}$ & 3 & 11 & 14 & $\begin{array}{c}\text { Fischers } \\
\text { Exact }\end{array}$ & 0.61 \\
\hline 6 & Left lamellar & 2 & 7 & 9 & $\begin{array}{c}\text { Fischers } \\
\text { Exact }\end{array}$ & 0.85 \\
\hline & TOTAL & 31 & 69 & 100 & & \\
\hline
\end{tabular}

free of ipsilateral osteomeatal unit blockage. Of the 23 cases of bulbous concha bullosa on the right side, 5 cases $(21.7 \%)$ had associated ipsilateral osteomeatal unit blockage and 18 cases $(78.3 \%)$ were free of ipsilateral osteomeatal unit blockage. Of the 8 cases of bulbous concha bullosa on the left side, 4 cases $(50 \%)$ had associated ipsilateral osteomeatal unit blockage and 4 cases $(50 \%)$ were free of ipsilateral osteomeatal unit blockage. Of the 14 cases of lamellar concha bullosa on the right side, 3 cases $(21.4 \%)$ had associated ipsilateral osteomeatal unit blockage and 11 cases (78.6\%) were free of ipsilateral osteomeatal unit blockage. Of the 9 cases of lamellar concha bullosa on the left side, 2 cases $(22 \%)$ had associated ipsilateral osteomeatal unit blockage and 7 cases $(78 \%)$ were free of ipsilateral osteomeatal unit blockage. (Table I)

On statistical analysis, we found no statistically significant association between any type of concha bullosa with osteomeatal unit block either in right side or left side. Even though the rhinosinusitis was more predominant in the extensive type of concha bullosa compared to other types, it was statistically not significant.

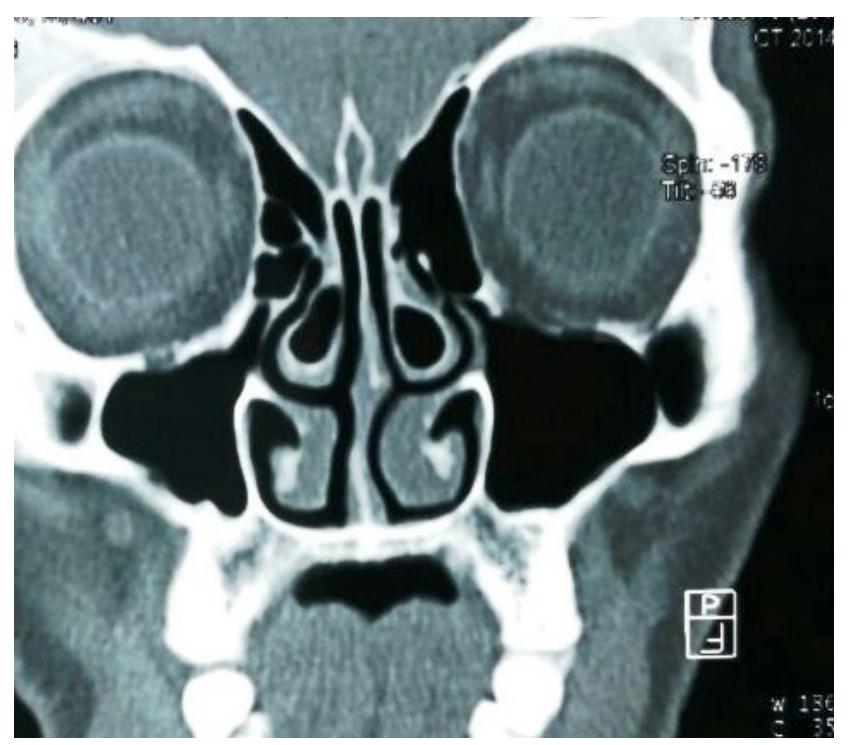

Fig.2. Bilateral bulbous type concha bullosa with bilateral normal osteomeatal units 


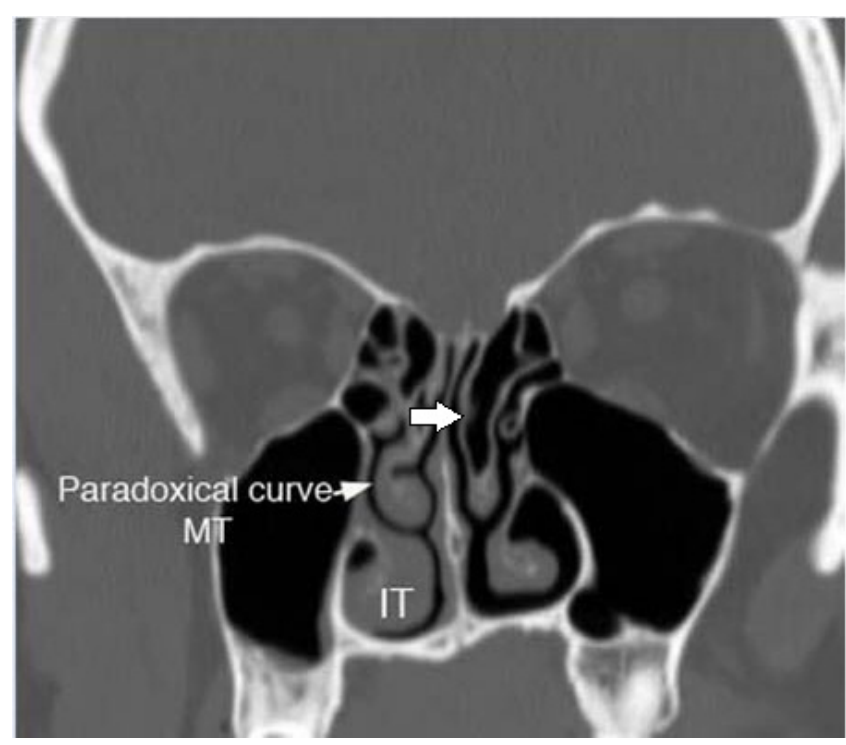

Fig.3. Left sided lamellar concha bullosa (bold arrow) with no osteomeatal unit blockage

\section{Discussion}

The exact mechanism of concha bullosa formation has been unclear. However, it is considered that the

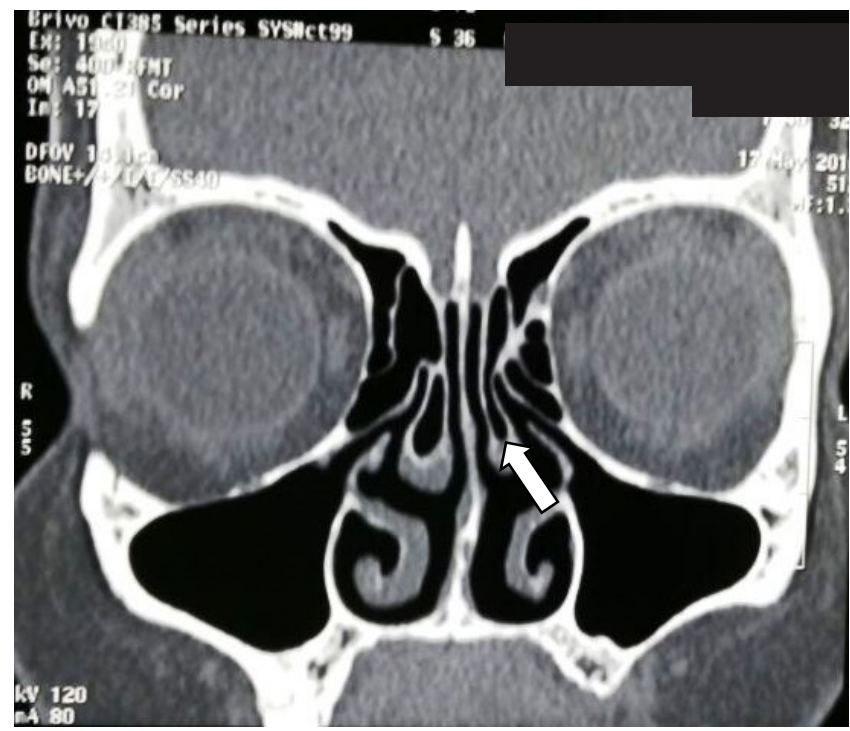

Fig.4. Right bulbous concha bullosa and left lamellar concha bullosa (arrow) with no osteomeatal block on both sides

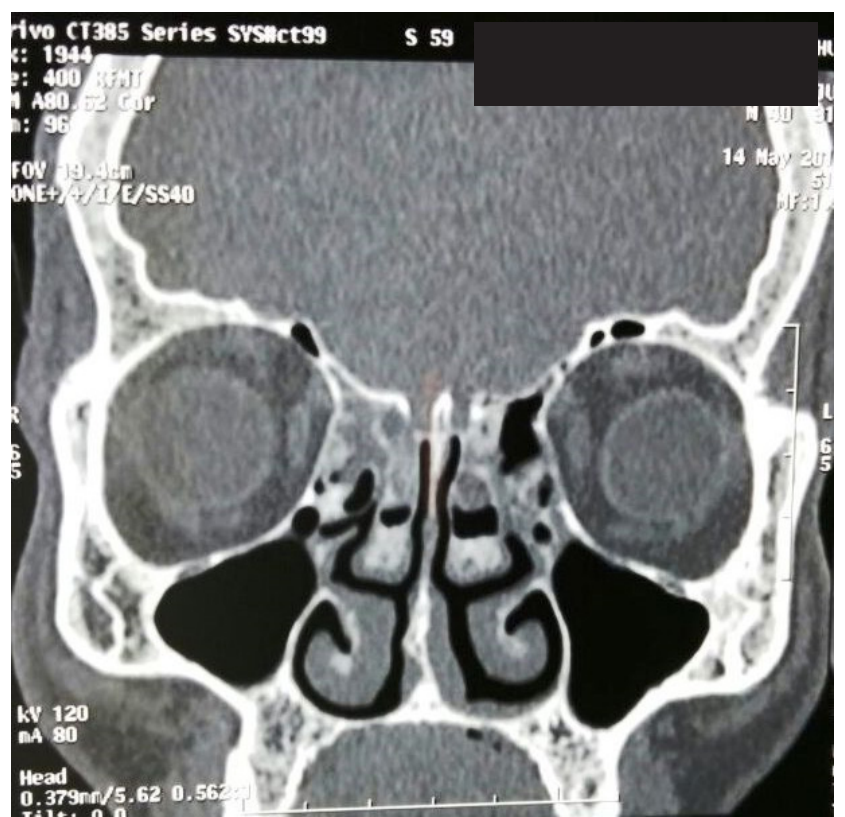

Fig.5. Bilateral lamellar type concha bullosae with bilateral osteomeatal block

airflow pattern of the nasal cavity plays an important role. This theory is named as "e vacue". As the airflow is markedly reduced in the nasal cavity with convexity of the deviation, pneumatisation of the middle turbinate is augmented in the contralateral site. ${ }^{8}$ This theory can explain the association between contralateral concha bullosa and nasal septal deviation. A study by Stalman at al. shows presence of contralateral nasal septal deviation in $69.5 \%$ of patients with unilateral concha bullosa or dominant concha bullosa. ${ }^{5}$

The frequency of concha bullosa in the literature ranges from $14-53 \%{ }^{1}$ Stallman defined concha bullosa as being present when more than $50 \%$ of the vertical height (measured from superior to inferior in the coronal plane) of the middle turbinate is pneumatised while Smith et al defined concha bullosa as the presence of pneumatisation of any size within the superior, middle or inferior conchae.${ }^{59}$ However, Hatipoğlu et al classified concha bullosa depending on the location of the pneumatisation as lamellar, bulbous and extensive. ${ }^{10}$ In his study, the incidence of concha bullosa was extensive type (46.95\%), bulbous type (32.17\%) and lamellar type (20.86\%). In the study by Unlu et.al, the incidence of concha bullosa was extensive type $(34.2 \%)$, bulbous 
type $(20.63 \%)$ and lamellar type $(45.23 \%) .{ }^{11}$ Tonai and Baba reported the incidence of concha bullosa as extensive type (52\%), bulbous type (19\%) and lamellar type $(2 \%){ }^{12}$ Bolger et al. reported the incidence of concha bullosa as extensive type $(15.7 \%)$, bulbous type $(46.2 \%)$ and lamellar type $(31.2 \%){ }^{2}$ Uygur et al reported the incidence of concha bullosa as extensive type (10.8\%), bulbous type (33.9\%) and lamellar type $(55.3 \%) .{ }^{13}$ In our study, the incidence of different types of concha bullosa was extensive type (46\%), bulbous type $(31 \%)$ and lamellar type $(23 \%)$. The variations may be due to differences between the study groups, differences in pneumatisation parameters and the analytical methods used.

It is to be noted that this is a cross-sectional observational study and not case control study. Hence, there is no control group in our study. In our study, we found no statistically significant association between any type of concha bullosa with rhinosinusitis either in right side or left side. Even though the rhinosinusitis was more predominant in the extensive type of concha bullosa compared to other types, it was statistically not significant. Some authors have reported that concha bullosa plays a role in recurrent sinusitis by compressing the uncinate process and obstructing or narrowing the infundibulum and the middle meatus., ${ }^{1,214,15,16}$ According to Lloyd et al, when concha bullosa fills the space between the septum and the lateral nasal wall, there may be total obstruction of the middle meatus orifice. ${ }^{15,16}$ Comparative studies involving asymptomatic patients and sinusitis patients have reported that concha bullosa is more frequently encountered in patients with sinusitis. ${ }^{15-17}$ It is significant to note that the comparative studies which failed to show a significant association between the sinus disease and concha bullosa were performed only on the symptomatic groups. ${ }^{11,18}$ There are studies pointing out that the size of concha bullosa is important for the presence of symptoms. ${ }^{13,14}$ Yousem et al. have advocated that concha bullosa is not one of the causes of sinusitis yet the size has implications. ${ }^{18}$ Stallman et al have demonstrated no significant association between the concha bullosa size and sinusitis. ${ }^{5}$ No consensus was achieved regarding this matter. We did not classify conchae bullosa by their sizes. ENT specialists believe that especially bulbous type concha bullosa with large dimensions may have a role in sinus disease. ${ }^{3}$ We studied the importance of concha bullosa location (lamellar, bulbous and extensive) in relation osteomeatal block, which predisposes to rhinosinusitis. In the most extensive study on this topic by Ünlü et al, no significant relation was demonstrated between concha bullosa and osteomeatal unit blockage; however, when the bulbous-extensive type was compared with the lamellar type, a significant correlation was found regarding osteomeatal unit blockage. ${ }^{11}$ They thus concluded that pneumatisation of the inferior portion of the middle concha has a role in osteomeatal unit blockage. No significant difference was found between the bulbous and extensive types in their study. ${ }^{11}$ This study is based on purely radiological assessment and clinical features were not included in the assessment. Future studies including clinical signs and symptoms along with the radiological parameter would through more light on the association between concha bullosa and rhinosinusitis.

\section{Conclusion}

There is no statistically significant association between any type of concha bullosa with rhinosinusitis. In our study, even though the rhinosinusitis was more predominant in the extensive type of concha bullosa compared to other types, it was statistically not significant. The limitation of our study was that our study group included only hospital visiting subjects and did not include any normal population. It is to be noted that this is a prospective cross-sectional observational study and not case control or cohort study. A bigger study with larger sample size will throw more light on the presence and strength of association between concha bullosa and rhinosinusitis.

\section{References}

1. Zinreich S, Albayram S, Benson M, Oliverio P. The osteomeatal complex and functional endoscopic surgery. In: Som P, ed. Head and Neck Imaging. 4th ed. St Louis: Mosby, 2003; 149-73

2. Bolger WE, Butzin CA, Parsons DS. Paranasal sinus bony anatomic variations and mucosal abnormalities: CT analysis for endoscopic sinus surgery. Laryngoscope 1991; 101:56-64

3. Stammberger H. Functional Endoscopic Sinus Surgery. 
Philadelphia: B. C. Decker, 1991; 161-9

4. Stammberger HR, Kennedy DW. Paranasal sinuses: anatomic terminology and nomenclature. The Anatomic Terminology Group. Ann Otol Rhinol Laryngol Suppl. 1995; 167:7-16

5. J. S. Stallman, J. N. Lobo, P. M. Som. The incidence of concha bullosa and its relationship to nasal septal deviation and paranasal sinus disease. Am J Neuroradiol. 2004; 25(9):1613-8

6. S. Subramanian, G. R. L. Rampal, E. F. M. Wong, S. Mastura, and A. Razi. Concha bullosa in chronic sinusitis. Medical Journal of Malaysia 2005; 60(5): 535-9

7. Rak KM, Newell JD, Yakes WF, Damiano MA, Iwethke JM. Paranasal sinuses on MRI images of the brain: Significance of mucosal thickening. Am J Radiol. 1991; 156: 381-4

8. Aktas D, Kalcioglu MT, Kutlu R, et al. The relationship between the concha bullosa, nasal septal deviation and sinusitis. Rhinology 2003; 41:103-6

9. Smith KD, Edwards PC, Saini TS, et al. The Prevalence of concha bullosa and nasal septal deviation and their relationship to maxillary sinusitis by volumetric tomography. Int J Dent. 2010; doi:10.1155/2010/404982.

10. Hatipoğlu HG, Cetin MA, Yüksel E. Concha Bullosa Types: their relationship with sinusitis, osteomeatal and frontal recess disease. Diag Interv Radiol. 2005; 11(3): 145-9
11. Ünlü HH, Akyar S, Çaylan R, Nalça Y. Concha bullosa. J Otolaryngol 1994; 23:23-7

12. Tonai A, Baba S. Anatomic variations of the bone in sinonasal CT. Acta Otolaryngol. 1996; 535:9-13

13. Uygur K, Tüz M, Doğru H. The correlation between septal deviation and concha bullosa. Otolaryngol Head Neck Surg. 2003; 129:33-6

14. Zinreich JS, Mattox DE, Kennedy DW, Chisholm HL, Diffley DM, Rosenbaum AE.Concha bullosa: CT evaluation. J Comput Assist Tomogr. 1988; 12:778-84

15. Lloyd GAS. CT of the paranasal sinuses: study of a control series in relation to endoscopic sinus surgery. J Laryngol Otol. $1990 ; 104: 477-81$

16. Lloyd GAS, Lund VJ, Scadding GK. CT of the paranasal sinuses and functional endoscopic surgery: a critical analysis of 100 symptomatic patients. J Laryngol Otol. 1991; 105:181-5

17. Calhoun KH, Waggenspack GA, Simpson CB, Hokanson JA, Bailey BJ. CT evaluation of the paranasal sinuses in symptomatic and asymptomatic populations. Otolaryngol Head Neck Surg. 1991; 104:480-3

18. Yousem DM. Imaging of the sinonasal inflammatory disease. Radiology 1993; 188: 303-14 